\title{
A novel Sugarcane bacilliform virus promoter confers gene expression preferentially in the vascular bundle and storage parenchyma of the sugarcane culm
}

\author{
San-Ji Gao ${ }^{1 \dagger}$, Mona B. Damaj ${ }^{2 \dagger}$, Jong-Won Park ${ }^{2+}$, Xiao-Bin Wu ${ }^{3}$, Sheng-Ren Sun ${ }^{1}$, Ru-Kai Chen ${ }^{1}$
} and T. Erik Mirkov*

\begin{abstract}
Background: Saccharum species such as sugarcane and energy cane are key players in the expanding bioeconomy for sugars, bioenergy, and production of high-value proteins. Genomic tools such as culm-regulated promoters would be of great value in terms of improving biomass characteristics through enhanced carbon metabolism for sugar accumulation and/or fiber content for biofuel feedstock. Unlike the situation in dicots, monocot promoters currently used are limited and mostly derived from highly expressed constitutive plant genes and viruses. In this study, a novel promoter region of Sugarcane bacilliform virus (SCBV; genus Badnavirus, family Caulimoviridae), SCBV21 was cloned and mapped by deletion analysis and functionally characterized transiently in monocot and dicot species and stably in sugarcane.

Results: In silico analysis of SCBV21 [1816 base pair (bp)] identified two putative promoter regions (PPR1 and PPR2) with transcription start sites (TSS1 and TSS2) and two TATA-boxes (TATAAAT and ATATAA), and several vascular-specific and regulatory elements. Deletion analysis revealed that the 710 bp region spanning PPR2 (with TSS2 and ATATAA) at the $3^{\prime}$ end of SCBV21 retained the full promoter activity in both dicots and monocots, as shown by transient expression of the enhanced yellow fluorescent protein (EYFP) gene. In sugarcane young leaf segments, SCBV21 directed a 1.8- and 2.4-fold higher transient EYFP expression than the common maize ubiquitin 1 (Ubi1) and Cauliflower mosaic virus 355 promoters, respectively. In transgenic sugarcane, SCBV21 conferred a preferential expression of the $\beta$-glucuronidase (GUS) gene in leaves and culms and specifically in the culm storage parenchyma surrounding the vascular bundle and in vascular phloem cells. Among the transgenic events and tissues characterized in this study, the SCBV21 promoter frequently produced higher GUS activity than the Ubi1 or 355 promoters in a manner that was not obviously correlated with the transgene copy number.
\end{abstract}

Conclusions: The newly developed plant viral SCBV21 promoter is distinct from the few existing SCBV promoters in its sequence and expression pattern. The potential of SCBV21 as a tissue-regulated promoter with a strong activity in the culm vascular bundle and its storage parenchyma makes it useful in sugarcane engineering for improved carbon metabolism, increased bioenergy production, and enhanced stress tolerance.

Keywords: Sugarcane bacilliform virus promoter, Tissue-regulated expression, Culm preferential expression, Storage parenchyma, Vascular bundle, Saccharum spp. hybrids

\footnotetext{
*Correspondence: e-mirkov@tamu.edu

${ }^{\dagger}$ San-Ji Gao, Mona B. Damaj, and Jong-Won Park contributed equally to this work

${ }^{2}$ Texas A\&M AgriLife Research, Weslaco, TX 78596, USA

Full list of author information is available at the end of the article
} 


\section{Background}

The development of genomic tools such as promoters that differ in their ability to regulate the temporal and spatial expression patterns of transgenes constitute a major priority for the genetic improvement of major crops and the production of new products at levels useful for commercialization. The use of promoters with different expression patterns is particularly desirable to minimize the risk of transgene silencing in multigene transformation, routinely applied to achieve more complex, and ambitious phenotypes in transgenic crops [1, 2]. Unlike the situation in dicots, monocot promoters currently used are relatively few and mostly derived from highly expressed constitutive plant genes, such as the Ubiquitin (Ubi) promoters, maize Ubi1 [3], sugarcane $u b 4$ and $u b 9$ [4], rice RUBQ2 [5], Porteresia coarctata Ubi2.3 [6], and Erianthus arundinaceus Eriubi D7 [7]. To date, tissue-specific monocot promoters have been developed that target gene expression in leaf and root, but only few are functional in stems. This is a crucial deficit for sugarcane (Saccharum spp. hybrids), a major sugar and biomass producer accounting for about $40 \%$ of the biofuel production worldwide [8]. Promoters functional in the sugarcane culm include sugarcane dirigent and $o$-methyltransferase from putative defense and fiber biosynthesis-related genes [9], maize phosphoenolpyruvate carboxylase [10, 11], and sugarcane Loading Stem Gene [12].

Intergenic regions of plant pararetroviruses (family Caulimoviridae) have the potential to be used as promoters and could be exploited in the expression of transgenes in monocots or dicots. These include the various enhanced $35 \mathrm{~S}$ promoters from the dicot-infecting DNA Cauliflower mosaic virus (CaMV) [13] or the promoters of monocot-infecting DNA viruses like Rice tungro bacilliform virus (RTBV) [14, 15], Commelina yellow mottle virus [16], Taro bacilliform virus [17], Banana streak virus (BSV) [18], and Sugarcane bacilliform virus (SCBV) $[19,20]$. Viral promoters derived from monocot-infecting DNA viruses are of particular interest because they tend to confer a tissue-specific gene expression, specifically in the vascular system $[14,16-20]$.

SCBV (genus Badnavirus, family Caulimoviridae), serologically related to BSV, have a double-stranded DNA genome of around 7.3-7.9 kilobase pair (kb) in size, encoding three open reading frames (ORFs) whose transcription is directed by a single promoter residing between ORF3 ( $3^{\prime}$ end) and ORF1 (5' end) [21-25]. SCBV promoters previously examined are derived from two distinct SCBV species recognized by the International Committee on Taxonomy of Viruses, Sugarcane bacilliform MO virus (SCBMOV-MOR) and Sugarcane bacilliform IM virus (SCBIMV-QLD), originating from
Morocco and Australia, respectively [21, 22, 26, 27]. SCBV isolates display a high degree of variability in their nucleotide (nt) sequence [23, 24, 28, 29], and SCBV promoters confer different patterns of gene expression in various plant species [30]. The natural diversity of SCBV could be exploited to isolate additional SCBV promoters with distinct expression patterns.

Few studies have been directed towards investigating the expression pattern of SCBV promoters in sugarcane. The successful use of such promoters depends to a large extent on overcoming the ability of highly polyploid species such as sugarcane to silence transgenes [31-34]. In this study, we report the development of a novel plant viral promoter, $S C B V 21$, isolated from a commercial sugarcane variety (CP72-1210) infected with a Texan SCBV isolate (SCBV-TX) and functionally active in sugarcane. Stable expression analyses demonstrated that $S C B V 21$ conferred a tissue-regulated gene expression, preferentially in leaves and culms and mainly in the storage parenchyma surrounding the vascular bundle and in vascular phloem and sclerenchyma of the sugarcane culm. It is further shown that $S C B V 21$ exhibited significantly higher levels of gene expression than the common maize Ubi1 and CaMV 35S promoters. The value of the SCBV21 promoter in functional gene analysis and in engineering high-biomass producers such as sugarcane and other monocot species for improved carbon metabolism, enhanced stress tolerance, and bioenergy production, is discussed.

\section{Methods}

Isolation and sequence analysis of the SCBV21 promoter

The intergenic region of the viral genome in the family Caulimoviridae is a potential promoter region (PPR) [27]. Hence, a set of primers, Prom-F and Prom-R (Additional file 1: Table S1) were designed from the conserved sites flanking the PPR based on multiple alignment of the nucleotide sequences of the two published SCBMOVMOR and SCBIMV-QLD promoters and an unpublished potential SCBV promoter fragment ( $2 \mathrm{~kb})$ (kindly provided by Dr. Guo-Hui Zhou, South China Agricultural University). A 1816-base pair (bp) fragment containing the $S C B V 21$ promoter was PCR amplified from leaf genomic DNA of commercial sugarcane variety CP721210 infected with SCBV-TX isolate, using the Prom$\mathrm{F}$ and Prom-R primers. PCR was performed in a total reaction volume of $20 \mu \mathrm{L}$ using Taq DNA polymerase (NEB BioLabs, Ipswich, MA, USA) following the manufacturer's recommendation with the cycling conditions: one cycle at $94{ }^{\circ} \mathrm{C}$ for $4 \mathrm{~min}, 35$ cycles each at $94{ }^{\circ} \mathrm{C}$ for $30 \mathrm{~s}, 52{ }^{\circ} \mathrm{C}$ for $30 \mathrm{~s}$, and $72{ }^{\circ} \mathrm{C}$ for $2 \mathrm{~min}$, and one cycle at $72{ }^{\circ} \mathrm{C}$ for $5 \mathrm{~min}$. The nt sequence of the amplified SCBV21 (Additional file 2: Figure S1) was deposited into 
GenBank under accession number KY031904. The PPR and transcription start site (TSS) of SCBV21 was identified in silico with Neural Network Promoter Prediction (http://www.fruitfly.org/seq_tools/promoter.html) [35], and putative cis-acting elements were predicted by PlantCARE (http://bioinformatics.psb.ugent.be/webtools/ plantcare) [36] and PLACE database for plant cis-acting regulatory DNA elements (https://sogo.dna.affrc.go.jp/ cgi-bin/) [37]. Motifs for plant transcription factors (TFs) associated with phloem or xylem histogenesis were identified in $S C B V 21$ by the plant TF database PlantTFDB version 4.0 (http://planttfdb.cbi.pku.edu.cn) [38]. Partial reverse transcriptase/ribonuclease $\mathrm{H}$ (RT/RNAse $\mathrm{H}) \mathrm{nt}$ sequences (782 nt) from the $S C B V 21$ promoter and corresponding regions of $12 \mathrm{SCBV}$ and three BSV genomes from GenBank were aligned with the ClustalW algorithm implemented in MEGA 6.0 [39]. Nucleotide sequences of the promoter regions of $S C B V 21$, SCBIMV-QLD, and SCBMOV-MOR were also aligned using the same algorithm. Nucleotide sequence identities were estimated by pair-wise sequence comparison using BioEdit programs [40].

\section{Expression vectors}

The amplified $S C B V 21$ promoter was subcloned into pGEM-T Easy vector (Promega, Madison, WI, USA) as $S C B V 21 / \mathrm{pGEM}-\mathrm{T}$. Three EYFP expression vectors were generated with $S C B V 21, \operatorname{Pr} 4$ [Ubi1 without heat-shock elements, a deletion of 25 bp (5'-TGGACCCCTCTCGA GAGTTCCGCTC- $3^{\prime}$ ) at the $5^{\prime}$ end of $U$ bil] and CaMV $35 \mathrm{~S}$ promoters (Additional file 3: Figure S2). The $S C B V 21: E Y F P / \mathrm{pSK}$ vector was produced by cloning the SalI/NcoI-released SCBV21 fragment of SCBV21/ pGEM-T as a transcriptional fusion with the EYFP gene in the SalI/NcoI-digested CaMV $2 \times 35 \mathrm{~S}: E Y F P-N O S / \mathrm{pSK}$ (pBluescript) vector [41], replacing the CaMV $2 \times 35 \mathrm{~S}$ promoter. The Pr4:EYFP/pSK construct was assembled by cloning the HindW/NcoI-released Pr4 fragment of Pr4:GUS/pUC19 (Invitrogen, Carlsbad, CA, USA) as a transcriptional fusion with EYFP into the HindW/NcoIdigested EYFP-NOS/pSK, replacing the CaMV $2 \times 35 \mathrm{~S}$ promoter. The 35S:EYFP-NOS/pSK vector was constructed by cloning the HindW/BamHI-released CaMV $35 \mathrm{~S}$ fragment from pBI221 (Clontech, Takara Bio USA, Inc., Mountain View, CA, USA) as a transcriptional fusion with the EYFP gene in the Ubi1:EYFP-NOS/ pSK vector [41] after digestion with two sets of restriction enzymes, BamHI and EcoRI, and EcoRI and HindW, replacing the Ubi1 promoter.

Three GUS expression vectors were generated with SCBV21, Ubi1, and CaMV 35S promoters. The $S C B V 21: G U S /$ pUC19 was constructed by cloning the NotI-released SCBV21 fragment from SCBV21/pGEM-T as a transcriptional fusion with the GUS gene to the SphI/XbaI-digested and blunt ended pBI221, replacing the CaMV 35S promoter. Ubi1:GUS/pUC19 (pAHC27) [3] and pBI221 (CaMV 35S:GUS) were used.

A series of $S C B V 21$ deletion constructs were generated from SCBV21:EYFP-NOS/pSK, using the three restriction enzymes $X h o I, N c o I$, and StuI. XhoI and NcoI sites were incorporated at the $5^{\prime}$ end of forward (SCBV-MF1 and SCBV-MF2) and reverse (SCBV-MR1 and SCBVMR2) primers, respectively (Additional file 1: Table S1). Deletion fragment $\Delta$ nt1014-nt1837 (deletion A) was generated by deleting the region between $\mathrm{Sut} \mathrm{I}$ and $\mathrm{Nco}$ I in SCBV21:EYFP-NOS/pSK, followed by blunt ending using the Klenow enzyme (NEB BioLabs). Deletion fragments $\Delta$ nt1-nt1010 (deletion B), $\Delta$ nt1-nt1105 (deletion C), $\Delta$ nt1-nt1010 and $\Delta$ nt1732-nt1837 (deletion D), and $\Delta$ nt1-nt1105 and $\Delta$ nt1732-nt1837 (deletion E) were PCR amplified from SCBV21:EYFP-NOS/pSK using the four sets of primers MF1/MR1, MF2/MR1, MF1/MR2, and MF2/MR2, respectively, and cloned in the blunt ended EYFP-NOS/pSK, replacing full-length SCBV21. All constructs were sequenced prior to further use to ensure integrity.

\section{Preparation of target tissue}

Transient EYFP and GUS gene expression assays were performed on sugarcane (Saccharum spp. hybrids) tissues (young leaf, top culm, and root), sweet sorghum (Sorghum vulgare) leaves, tobacco (Nicotiana benthamiana) leaves, and lima bean (Phaseolus lunatus L.) cotyledons. Sugarcane young leaf segment, leaf roll and top culm were collected from field-grown varieties CP72-1210 and CP84-1198 and prepared as previously described [34, 41]. Leaf segments and rolls were cultured on MS0.6 medium $[42,43]$ for 3-4 and 7-10 days in the dark before transformation, respectively. The top young shoot culms were excised approximately $1 \mathrm{~cm}$ thick and used immediately. Roots, collected from 3 month-old greenhouse-grown plants, were sterilized in $10 \%(\mathrm{v} / \mathrm{v})$ commercial bleach for $20 \mathrm{~min}$ and rinsed three times with sterile water before transformation.

Young leaf segments of field-grown sweet sorghum were prepared the same way as sugarcane $[34,41]$ and incubated on MS0.6 medium for 3-4 days in the dark prior to transformation. $N$. benthamiana seeds were sterilized and germinated on MS medium for 1-2 months before seedling leaves were excised and transformed. Cotyledonary tissue from germinating lima bean seeds was prepared according to Chiera et al. [44]. Briefly, seeds were sterilized in $10 \%(\mathrm{v} / \mathrm{v})$ commercial bleach for $20 \mathrm{~min}$, washed three times with sterile water, and kept in Magenta GA7 containers between layers of a folded white paper towel saturated with sterile water 
$(25 \mathrm{~mL})$ for 4 days at $26 \pm 1{ }^{\circ} \mathrm{C}$ under $16 \mathrm{~h}$ of illumination $\left(40 \mu \mathrm{Em}^{-2} / \mathrm{s}\right)$. The light green cotyledons were excised from the germinating seedlings prior to transformation.

\section{Plant transformation and generation of transgenics}

All tissues were incubated on MSO medium (MS0.6 with $36.44 \mathrm{~g} / \mathrm{L}$ D-mannitol and $36.44 \mathrm{~g} / \mathrm{L} \mathrm{D}$-sorbitol) prior to transformation by particle bombardment. DNA coating for bombardment was performed according to Beyene et al. [41]. Briefly, tungsten particles $(1.1 \mu \mathrm{m}$, Bio-Rad Laboratories, Hercules, CA, USA) (1 mg) were coated separately with plasmid DNA $(1.0 \mu \mathrm{g})$ of different constructs using calcium chloride $(33.4 \mu \mathrm{L}$ of $2.5 \mathrm{M})$ and spermidine $(13.4 \mu \mathrm{L}$ of $0.1 \mathrm{M})$. A total of $4 \mu \mathrm{L}$ of the DNA particle suspension $(0.5 \mu \mathrm{g}$ of plasmid DNA per bombardment) was placed in the center of a syringe filter and delivered into tissue with a particle inflow gun using a 1100 psi rupture disk, 26 in. $\mathrm{Hg}$ vacuum and $7 \mathrm{~cm}$ target distance. Bombarded tissue was maintained on MS0.6 medium at $26 \pm 1{ }^{\circ} \mathrm{C}$ in the dark until analysis.

For stable gene expression, Ubi1:bar (pAHC20) [3] was co-bombarded with the target construct into leaf roll discs. Following bombardment, leaf roll discs were maintained on MS0.6 medium for 7 days in the dark without selection, and then broken into small pieces and incubated on MS0.6 with Bialaphos $(4 \mathrm{mg} / \mathrm{L})$ selection for 2 weeks. Subsequently, resistant calli derived from leaf rolls were placed on MS with kinetin $(2 \mathrm{mg} / \mathrm{L})$, naphthalene acetic acid $(2 \mathrm{mg} / \mathrm{L})$, and Bialaphos $(4 \mathrm{mg} / \mathrm{L})$ for 6-8 weeks under a $16 \mathrm{~h}$ light/ $8 \mathrm{~h}$ dark cycle. Shoots were produced and transferred to MS rooting medium containing indole-3-butyric acid $(4 \mathrm{mg} / \mathrm{L})$ and Bialaphos $(4 \mathrm{mg} / \mathrm{L})$. After 4 weeks, rooted seedlings were transplanted into pots in the greenhouse. Screening of seedlings for presence of the selection marker Bialaphos was done by spraying with the herbicide glufosinate ammonium $(11.33 \%)(15 \mathrm{~mL} / \mathrm{L})$. Seedlings that survived were grown in the greenhouse for 2-12 months for further analysis.

\section{Southern blot analysis}

Identification of independent transgenic lines was done by Southern blot analysis. Genomic DNA was isolated from leaves using the SDS method [45]. Genomic DNA $(10 \mu \mathrm{g})$ was digested overnight with HindIII, separated on a $1 \%(\mathrm{w} / \mathrm{v})$ agarose gel and blotted onto a nylon membrane in $0.4 \mathrm{M}$ alkaline solution [46]. A GUS probe was generated from Pr4:GUS/pUC19 by BbsI/SacI digestion and labeled with $\left[\alpha{ }^{32} \mathrm{P}\right] \mathrm{dCTP}$ using the Random Primers DNA Labeling kit (Invitrogen, Carlsbad, CA). Pre-hybridization, hybridization, washing, and detection of DNA gel blots were conducted as described by Sambrook et al. [47] and Mangwende et al. [48], using Church's buffer.

\section{Analysis of $\beta$-glucuronidase activity}

Histochemical analysis of $\beta$-glucuronidase (GUS) activity was performed mainly as described by Jefferson et al. [49], using GUS buffer [0.1\% (v/v) Triton X-100 and $50 \mathrm{mM}$ sodium phosphate buffer, $\mathrm{pH}$ 7.0] with X-Gluc (5-bromo-4-chloro-3-indolyl- $\beta$-D-glucuronic acid) (1.0 mM, dissolved in DMF) and the oxidation catalysts, potassium ferricyanide, and potassium ferrocyanide (0.5 mM each, dissolved in $10 \mathrm{mM}$ EDTA, $\mathrm{pH}$ 8.0). Stained plant tissues were photographed with a zoom stereomicroscope (Olympus SZX7, Olympus, Center Valley, PA, USA). Quantitative GUS activity was carried out using 4-methylumbelliferyl- $\beta$-D-glucuronide (Rose Scientific Ltd., Alberta, Canada) [34, 49]). Fluorescence (emission of $455 \mathrm{~nm}$ and excitation of $365 \mathrm{~nm}$ ) was measured with a VersaFluor (Bio-Rad Laboratories). Protein concentrations were determined with the Bio-Rad protein assay kit.

\section{Evaluation of EYFP expression}

Images of different tissues expressing EYFP were collected at $48 \mathrm{~h}$ post-DNA bombardment using a stereomicroscope (Olympus SZX7, Olympus) fitted with YFPHQ filters (excitation of $490-500 \mathrm{~nm}$ and emission of 515$560 \mathrm{~nm}$ ) and a DP71 digital camera (Olympus). Colored RGB images $(4080 \times 3072$ pixels $)$ of leaf segments were collected using the same stereomicroscope $(15 \times)$. EYFP expression analysis was quantified using the ImageJ software (Rasband 1997-2009) as described by Chiera et al. [44]. The detailed protocol was provided by Gao et al. [34].

\section{Statistical analysis}

The GLM procedure of Statistical Analysis System (8.0 version, SAS Institute, USA) was used for statistical analysis. Multiple comparisons of the means were conducted by the Student-Newman-Keuls (SNK) Test. Pearson correlation analysis (SAS software) was performed on GUS activity and GUS copy number (as identified by Southern blot analysis) of the generated GUS transgenic lines.

\section{Results}

\section{Sequence analysis of SCBV21}

The 1826-bp SCBV21 amplified fragment (from SCBVTX isolate), located at the $3^{\prime}$ end of the SCBV genome, consisted of partial RT/RNAse $\mathrm{H}$ genomic $(\sim 0.8 \mathrm{~kb}$ near the $5^{\prime}$ end) and $\sim 1.0 \mathrm{~kb}$ promoter regions (Additional file 2: Figure S1). In silico analysis of $S C B V 21$ sequence with Neural Network Promoter Prediction (NNPP, version 2.2) identified two PPRs, PPR1 (1055-1105 nt) with transcription start site TSS1 (Fig. 1a; Additional file 2: Figure S1), and PPR2 (1737-1787 nt) with transcription start site TSS2 (Fig. 1b; Additional file 2: Figure S1). Two 
a

SCBV-TX
SCBMOV-MOR
SCBIMV-QLD
SCBV-CHN1
SCBV-CHN2
SCBV-BO91
SCBV-Iscam
SCBV-BB
SCBV-BT
SCBV-BRU
SCBGAV-R570
SCBGAV-B51129
SCBGDV-Batavia
BSOLV-NI
BSMYV-AUS
BSGFV-EC
Consensus

\section{b}

SCBV-TX
SCBMOV-MOR
SCBIMV-QLD
SCBV-CHN1
SCBV-CHN2
SCBV-BO91
SCBV-Iscam
SCBV-BB
SCBV-BT
SCBV-BRU
SCBGAV-R570
SCBGAV-B51129
SCBGDV-Batavia
BSOLV-NI
BSMYV-AUS
BSGFV-EC
Consensus

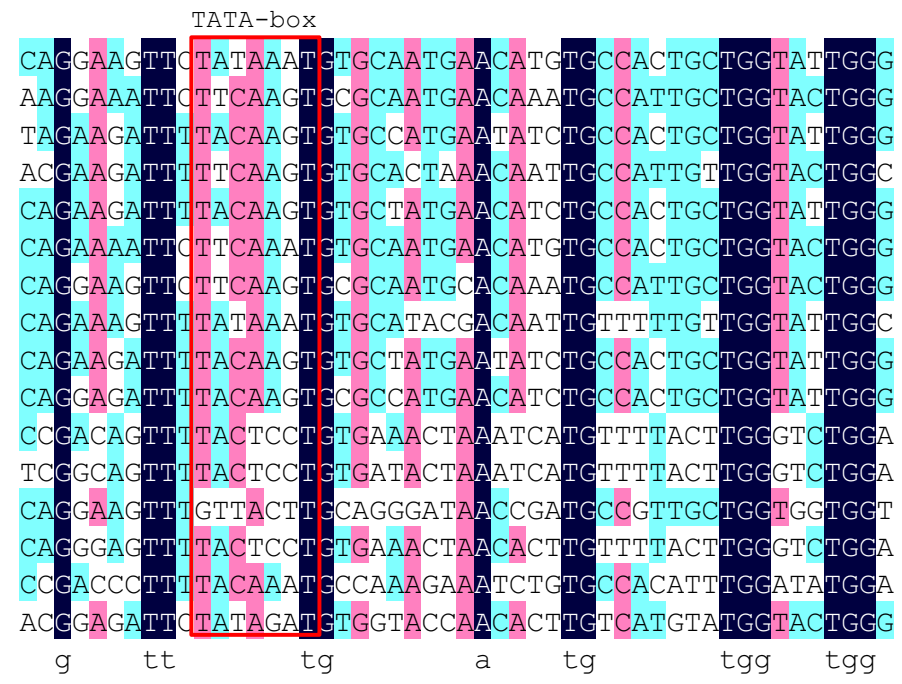

TATA-box

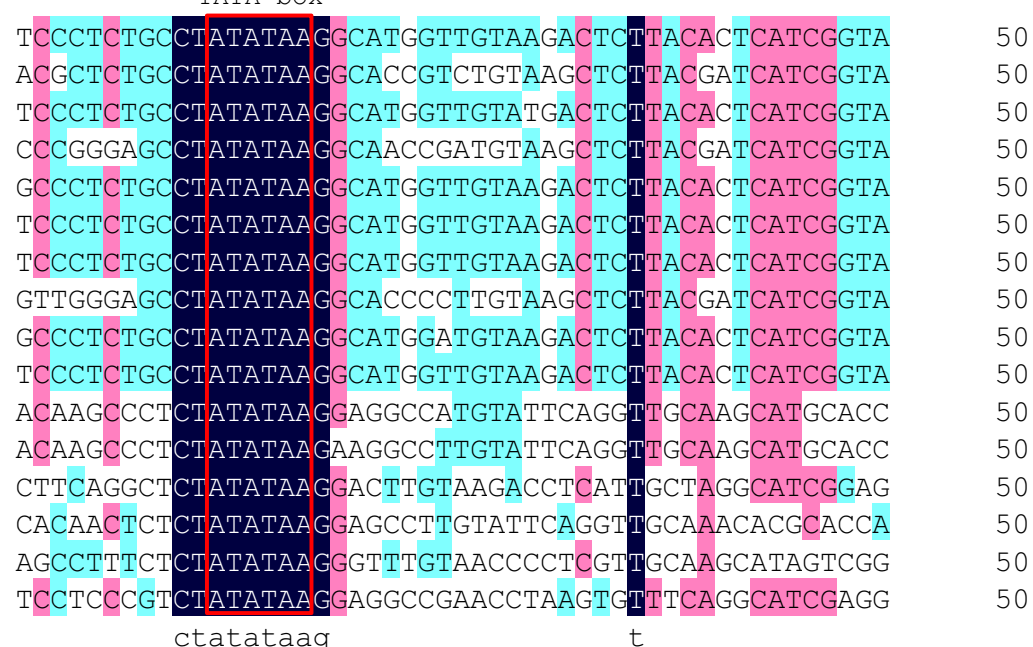

Fig. 1 Multiple nucleotide sequence alignments of SCBV21 [two potential promoter regions (PPRS)], 12 SCBV, and three BSV published isolates using DNAMAN 8.0. The sequence of isolate SCBV-TX (KY031904) was determined in this study, while sequences of isolates SCBMOV-MOR (NC_008017), SCBIMV-QLD (NC_003031), SCBV-CHN1 (KM214357), SCBV-CHN2 (KM214358), SCBV-BO91 (JN377533), SCBV-Iscam (JN377534), SCBV-BB (JN377535), SCBV-BT (JN377536), SCBV-BRU (JN377537), SCBGAV-R570 (FJ824813), SCBGAV-B51129 (FJ824814), SCBGDV-Batavia (FJ439817), BSOLV-NI (NC_003381), BSMYV-AUS (NC_006955), and BSGFV-EC (NC_007002) were obtained from the GenBank database. a, b Two PPRs of SCBV21 were identified by Neural Network Promoter Prediction (NNPP, version 2.2). The two TATA-boxes (TATAAAT and ATATAA) that were predicted by PlantCARE and PLACE databases are indicated in a red box. Nucleotides that are highlighted in black have the highest percentage identity
TATA-boxes (TATAAAT and ATATAA) were observed in PPR1 and PPR2, respectively. Seven CAAT-box and one CAT-box common cis-acting elements related to enhancer elements and meristem expression [50, 51], respectively, were found in $S C B V 21$ (Table 1).

Multiple nt sequence alignment of the two PPRs of $S C B V 21$ and those of 12 SCBV and three BSV published isolates comprising BSGFV-EC, BSMYV-AUS, and BSOLV-NI revealed that the TATAAAT sequence in PPR1 of SCBV21 was found only in SCBV-TX and SCBV-BB isolates (Fig. 1a), whereas the ATATAA sequence in PPR2 of $S C B V 21$ was conserved among the different SCBV and BSV isolates (Fig. 1b). Since the difference $(>20 \%)$ in $\mathrm{RT} / \mathrm{RNase} \mathrm{H}$ nt sequence is used as a species demarcation criterion in the Badnavirus genus [27], the pair-wise sequence comparison of the partial RT/RNase $\mathrm{H}$ sequences of $S C B V 21$ and the published SCBV and BSV isolates showed that the 
Table 1 Putative regulatory motifs enriched in the SCBV21 promoter

\begin{tabular}{|c|c|c|}
\hline Motif name and sequence $^{a}$ & Occurrence and position of motif ${ }^{b}$ & Function \\
\hline Tissue-specific motifs & & Expression in phloem, shoot, root, meristem \\
\hline ASL-box: CTTTA & $2(844 ; 1631)$ & \\
\hline Plant transcription factor motifs & & Biological process phloem or xylem biogenesis \\
\hline Motif 1: AAAAGGGAGCAAAAGGATTAA & $1(298-318)$ & \\
\hline Motif 2: TTGAACGATGATTAT & $1(1288-1302)$ & \\
\hline Motif 3: ATAAAGAAGCTAAAGCTGAAT & $1(1252-1272)$ & \\
\hline Motif 4: TGAAGAAGGATAAAGAAGCTA & $1(1243-1263)$ & \\
\hline Enhancer element motif & & Enhancement of gene expression \\
\hline CAAT-box: CAAT & $7(909 ; 1075 ; 1201 ; 1475 ; 1511 ; 1540 ; 1558)$ & \\
\hline Meristem-regulated motif & & Meristem-regulated gene expression \\
\hline CAT-box: CAT & $1(1087)$ & \\
\hline
\end{tabular}

RT/RNAse $\mathrm{H}$ of $S C B V 21$ shared only $56.5-88.7$ and $56.0-60.0 \%$ sequence identities with the $12 \mathrm{SCBV}$ and three BSV published isolates, respectively (Additional file 4: Table S2). Sequence identities of 78.4 and $88.7 \%$ were observed between SCBV-TX and SCBMOV-MOR and SCBIMV-IM, respectively, based on the RT/RNAse $\mathrm{H}$ analysis (Additional file 4: Table S2). Furthermore, SCBV-TX shared only 76.4 and $61.4 \%$ nt sequence identity with the published SCBIMV-QLD and SCBMOVMOR promoters, respectively, based on analysis of the full promoter regions ( 1826 bp) (Additional file 2: Figure $\mathrm{S} 1$ ).

\section{The SCBV21 core region is PPR2}

In order to map an active promoter region within the cloned 1816-bp SCBV21 fragment, a series of deletions were made around the two putative promoter regions, PPR1 and PPR2 (Fig. 2a). Each deletion was fused to EYFP and its promoter activity was tested transiently in sugarcane young leaf segments (Fig. 2b, c). As shown in Fig. 2b, c, a deletion of $824 \mathrm{nt}$ at the $3^{\prime}$ end of SCBV21 containing PPR1 and PPR2 (deletion A: $\Delta$ nt1014-nt1837) abolished its promoter activity. On the other hand, a deletion of $1010 \mathrm{nt}$ at the $5^{\prime}$ end of SCBV21 (deletion B: $\Delta$ nt1-nt1010) with a longer deletion containing PPR1 at the $5^{\prime}$ end of deletion B (deletion C: $\Delta$ nt1-nt1105) did not affect the promoter activity. However, deletion of PPR2 located at the $3^{\prime}$ end of SCBV21 (deletion D: $\Delta$ nt1-nt1010 and $\Delta$ nt1732-nt1837 and deletion E: $\Delta$ nt1-nt1105 and $\Delta$ nt1732-nt1837) showed a significant decrease in EYFP expression.

\section{SCBV21 directs transient EYFP gene expression} in monocots and dicots

To check if $S C B V 21$ is active in monocots and dicots, each of SCBV21:EYFP and SCBV21:GUS DNA (Additional file 3: Figure S2) was bombarded into leaf roll, stem and root of sugarcane, sweet sorghum young leaf, $N$. benthamiana leaf, and cotyledons of germinating seeds of lima bean. Tissue bombardment experiments demonstrated that $S C B V 21$ directed EYFP and GUS gene expression transiently in all tested tissue types (leaves, stems, and roots) in both monocots (sugarcane and sweet sorghum) and dicots ( $N$. benthamiana and lima bean) (Additional file 5: Figure S3).

To compare the activity of $S C B V 21$ with that of four common promoters, CaMV 35S, CaMV $2 \times 35 \mathrm{~S}$, Ubi1, and Pr4, EYFP were fused to each promoter (Additional file 3: Figure S2) and its expression was measured in sugarcane young leaf segments post-DNA bombardment (Fig. 3). The kinetics of EYFP gene expression revealed that the maximum level of expression was at $48 \mathrm{~h}$ postDNA bombardment (data not shown). Based on the EYFP foci count and signal intensity as quantified with Image [34], the activity of $S C B V 21$ and CaMV $2 \times 35$ S was significantly $(p<0.05)$ stronger than that of Ubi1, Pr4 and CaMV 35S (Fig. 3). The EYFP foci count for Ubi1, Pr4 and CaMV $35 \mathrm{~S}$ were about $75.5,70.2$ and $66.4 \%$ of that of $S C B V 21$, and the EYFP expression value was 54.8, 45.9 and $42.2 \%$ of that of $S C B V 21$, respectively (Fig. 3). However, EYFP expression levels driven by $S C B V 21$ in sugarcane leaf segments were as high as those driven by CaMV $2 \times 35 \mathrm{~S}$ 
a

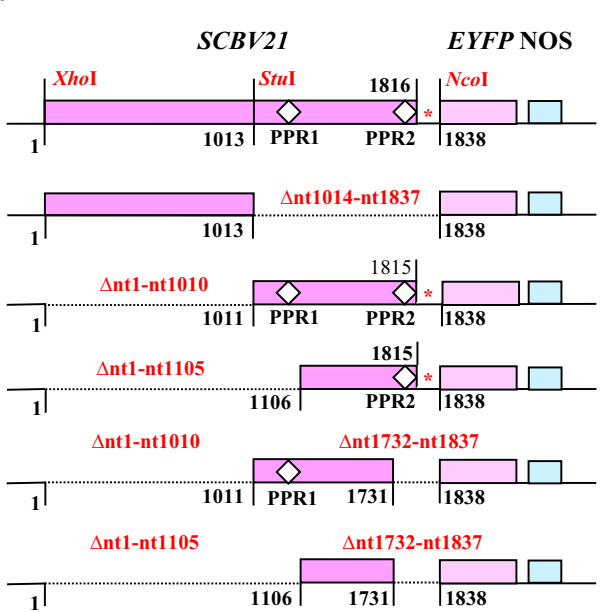

b

SCBV21 deletion

SCBV 21

A: $\Delta$ nt1014-nt1837

B: $\Delta$ nt 1-nt 1010

C: $\Delta$ nt1-nt1105

D: $\Delta$ nt1-nt1010 \&

$\Delta$ nt1732-nt1837

E: $\Delta$ nt1-nt1105 \& $\Delta \mathrm{nt} 1732$-nt1837

$\begin{array}{llll}\begin{array}{l}\text { SCBV21 } \\ \text { size (bp) }\end{array} & \text { PPR1 } & \text { PPR2 } & \begin{array}{l}\boldsymbol{E Y F P} \\ \text { expression }\end{array} \\ 1816 & \text { Yes } & \text { Yes } & +++ \\ 1013 & \text { No } & \text { No } & - \\ 805 & \text { Yes } & \text { Yes } & +++ \\ 710 & \text { No } & \text { Yes } & +++ \\ & & & \\ 721 & \text { Yes } & \text { No } & + \text { +- } \\ & & & \\ 626 & \text { No } & \text { No } & +/-\end{array}$

c
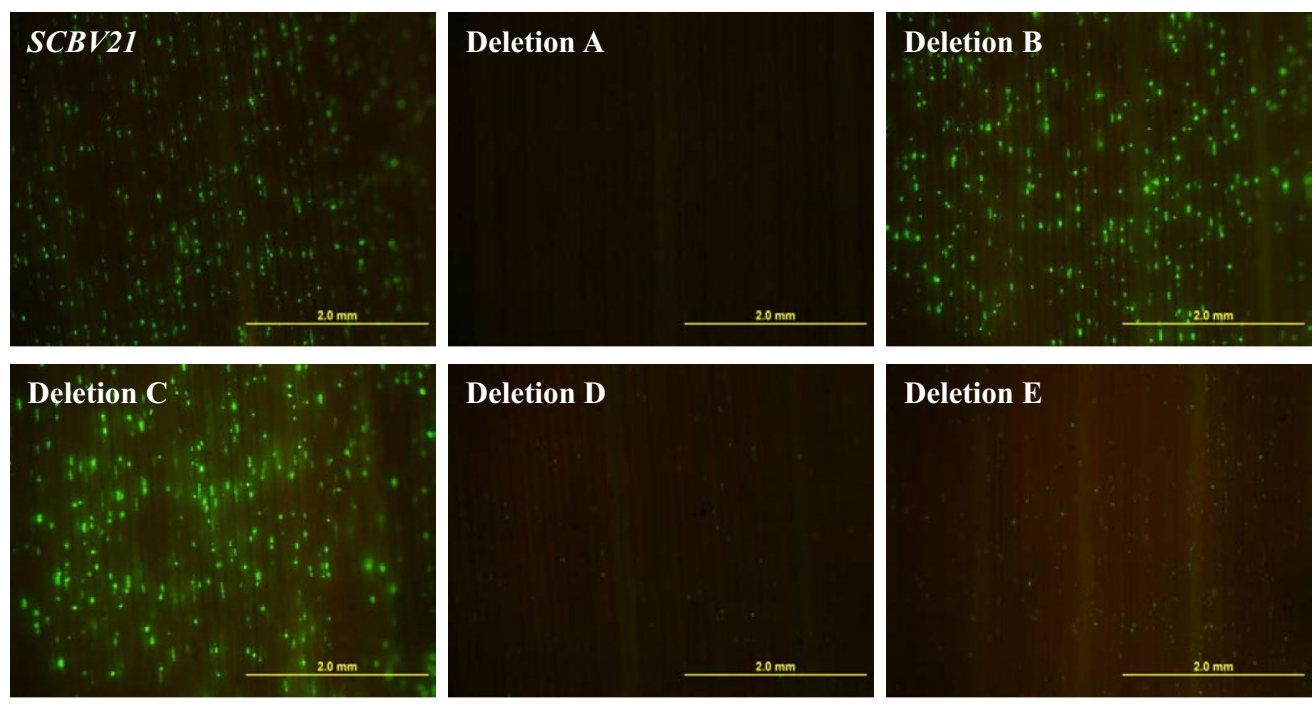

\section{Deletion E}

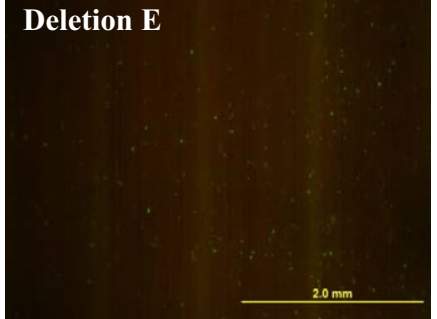

Fig. 2 Transient EYFP gene expression as directed by SCBV21 and its deletions in sugarcane. a Schematic map of full-length SCBV21 [1816 base pair (bp)] and its deletions. Nucleotide (nt) 1 is the first nt at the $5^{\prime}$ end of SCBV21. Deletions are indicated by dotted lines and their nt position of each deletion is indicated above the dotted line. The region between SCBV21 and EYFP, marked with an asterisk (*) in deletion A, is derived from the multicloning site of pGEM T-Easy vector and is removed from all deletion fragments. In deletions $C$ and D, the guanine base (G) at nt 1816 was deleted during cloning. Three important restriction enzyme sites, Xhol, Stul, and Ncol used for deletions are marked in deletion A. The two potential promoter regions (PPR1 and PPR2) of SCBV21, which are $632 \mathrm{bp}$ apart from each other, are shown with unfilled square boxes. The approximate position of primers used to generate deletions is indicated with filled arrowheads. b, c Monitoring of transient EYFP expression as directed by SCBV21 and its deletions in sugarcane young leaf segments. Representative images were collected with a stereomicroscope (Olympus SZX7, Olympus) fitted with YFPHQ filters (excitation of 490-500 nm and emission of 515-560 nm) and a DP71 digital camera (Olympus) ( $\times 15$ magnification) for $48 \mathrm{~h}$ postDNA bombardment (scale bar $2.0 \mathrm{~mm})$. EYFP expression levels were scored as high $(+++)$, medium $(++)$, low $(+)$, and none $(-)$, based on the EYFP focus count and EYFP expression level (mean gray value $\times$ pixels)

\section{SCBV21 directs GUS gene expression in a tissue-regulated manner in transgenic sugarcane}

Several sugarcane lines transgenic for SCBV21:GUS, Ubi1:GUS, and CaMV 35S:GUS were generated, as identified by Southern blot analysis with a range of GUS copy number of $8-14,13-19$, and $4-23$, respectively
(Table 2). No significant $(p>0.05)$ correlation between GUS activity and GUS copy number of the SCBV21:GUS, Ubi1:GUS, and 35S:GUS lines was found.

Quantitative analysis indicated that GUS activity levels of SCBV21:GUS sugarcane plants were significantly higher in culms than in leaves and roots (Table 2). 


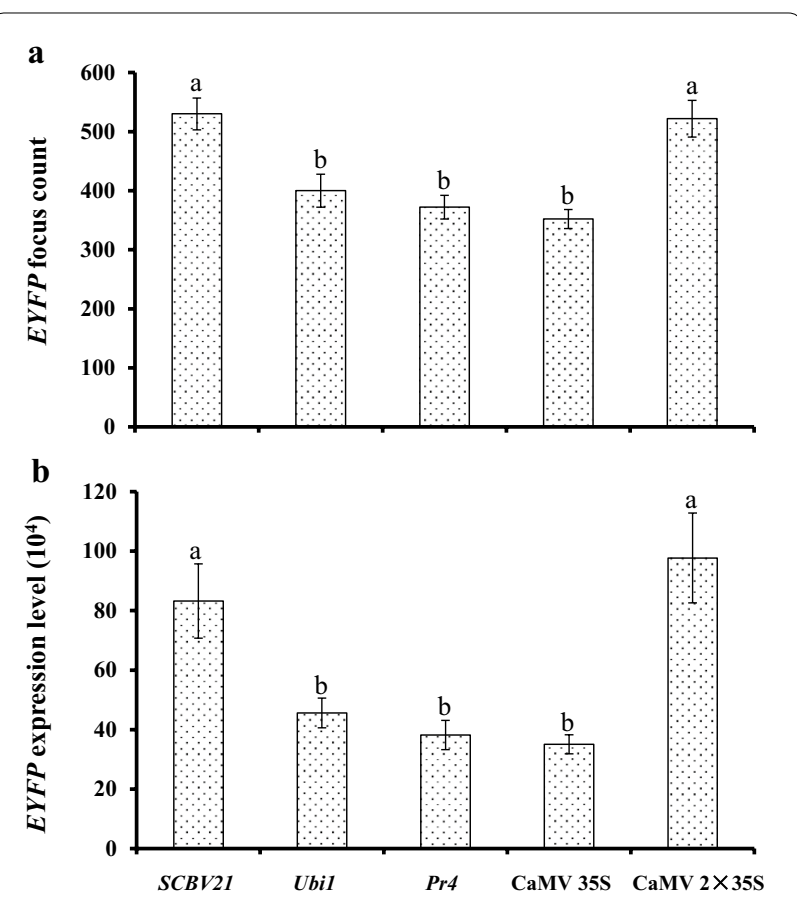

Fig. 3 Quantitative assessment of transient EYFP gene expression as directed by SCBV21, Ubi1, Pr4, CaMV 35 S or enhanced CaMV 35S $(2 \times 35 S)$ in sugarcane young leaf segments. Values of a EYFP focus count and $\mathbf{b}$ total EYFP expression level $\left(10^{4}\right)$ (mean gray value $\times$ pixels) were collected from representative images monitored with a stereomicroscope (Olympus SZX7, Olympus) fitted with YFPHQ filters (excitation of 490-500 nm and emission of 515-560 nm) and a DP71 digital camera (Olympus) ( $\times 15$ magnification) at $48 \mathrm{~h}$ post-DNA bombardment and calculated using ImageJ software as described in "Methods". Values represent means with standard error from three independent experiments and nine replicates per experiment. Means with the same letter are not significantly different at $p>0.05$

Increases in GUS activity of SCBV21:GUS sugarcane culms were 2.1-fold higher compared to leaves and 16.0-fold higher compared to roots. GUS activity driven by $S C B V 21$ increased 112-fold in culm and 27.0-fold in leaf compared to that driven by Ubi1 and 697-fold in culm and 969-fold in leaf, compared to that directed by CaMV 35S (Table 2). GUS activity driven by $S C B V 21$ was enhanced by 2.8 - and 23.0 -fold in root compared to that driven by Ubi1 and CaMV 35S, respectively (Table 2). $S C B V 21$ conferred high GUS activity in sugarcane culm tissue, irrespective of different spatial positions (top, middle, and bottom) (Table 3) and no significant difference in GUS activity was detected among the SCBV21:GUS transgenics (Table 3).

Significant GUS expression was histochemically detected in culms, especially in nodes and vascular bundles of transgenic sugarcane carrying SCBV21:GUS (Fig. $4 \mathrm{a}-\mathrm{c}$ ). GUS expression was also detected in leaves (Fig. 4d) and root tips (Fig. 4e).

\section{SCBV21 confers GUS gene expression in the sugarcane culm vascular bundle and storage parenchyma}

Histochemical GUS localization of SCBV21-driven GUS expression revealed that the $S C B V 21$ promoter conferred vascular GUS expression in the culm (Fig. 4), associated with the phloem and sclerenchyma cells of the vascular complex and with the storage parenchymatous tissue surrounding the vascular bundle (Fig. 5a, b). In silico analysis of the $S C B V 21$ sequence predicted the presence of the ASL-box (CTTTA repeat) [52,53] and four motifs of plant TFs previously associated with phloem histogenesis $[54,55]$ (Table 1), with three located at nt 1243-1302 between PPR1 and PPR2 and one in the RT/RNAse $\mathrm{H}$ region (Table 1).

\section{Discussion}

We have expanded the repertoire of promoters available for use in monocots by developing a novel plant viral promoter, $S C B V 21$, that is preferentially expressed in the culm vascular bundle and the storage parenchyma surrounding the bundle. The activity of $S C B V 21$ in monocots and dicots was evaluated by adopting a transient gene expression assay, previously shown to be rapid, quantifiable, and reproducible for the comparative analysis of the activity of different promoters [34, 41]. Transient

Table 2 The SCBV21 promoter drives expression of the GUS gene preferentially in the sugarcane culm and leaf

\begin{tabular}{lcccc}
\hline Transgenic line & GUS copy number & \multicolumn{4}{l}{ GUS activity (pmol of 4-methylumbelliferone/min/ $\mathbf{\mu g}$ protein) } & \\
\cline { 3 - 5 } & & Culm & Leaf & Root \\
\hline SCBV21:GUS & $8-14$ & $2649.1 \pm 41.3(2466.3-3252.1)$ & $1260.0 \pm 201.8(1127.9-1384.8)$ & $165.3 \pm 4.8(126.0-233.9)$ \\
Ubi1:GUS & $13-19$ & $23.6 \pm 1.5(18.3-42.5)$ & $46.6 \pm 2.6(31.6-57.4)$ & $58.1 \pm 9.0(37.1-80.1)$ \\
35S:GUS & $4-23$ & $3.8 \pm 0.9(2.0-5.4)$ & $1.3 \pm 0.2(0.4-3.0)$ & $7.2 \pm 0.3(5.5-9.0)$ \\
Nontransformed & & $8.8 \pm 0.5(0.5-13.0)$ & $0.5 \pm 0.03(0.05-0.1)$ & $3.9 \pm 0.1(3.6-4.3)$ \\
\hline
\end{tabular}

a Average GUS activity was measured in culms, leaves and roots of 1 year-old sugarcane transgenic for SCBV21:GUS. Ubi1:GUS and 35S:GUS lines were included as a positive control. The number of independent SCBV21:GUS, Ubi1:GUS and 35S:GUS transgenic lines tested were 5, 5 and 7, respectively. GUS activity represents three technical repetitions and is reported with the standard error. The range of GUS activities for each set of experiments is indicated in parentheses 
Table 3 The SCBV21 promoter drives high levels of GUS gene expression in the sugarcane culm

\begin{tabular}{llll}
\hline $\begin{array}{l}\text { SCBV21:GUS } \\
\text { transgenic line }\end{array}$ & \multicolumn{4}{l}{$\begin{array}{l}\text { GUS activity (pmol of 4-methylumbellifer- } \\
\text { one/min/ } \mathbf{\mu g} \text { protein) }\end{array}$} \\
\cline { 2 - 4 } & Top & \multicolumn{3}{c}{ Middle } & Bottom \\
\hline 5A (CP84-1198) & $2648.8 \pm 27.5$ & $2535.4 \pm 48.6$ & $2466.3 \pm 59.3$ \\
3501 (CP72-1210) & $2560.0 \pm 49.4$ & $2500.8 \pm 40.4$ & $2574.8 \pm 34.6$ \\
3512 (CP72-1210) & $2668.5 \pm 13.1$ & $2668.5 \pm 9.9$ & $2688.3 \pm 58.9$ \\
3515 (CP72-1210) & $2653.7 \pm 39.5$ & $2569.9 \pm 74.6$ & $3252.1 \pm 42.2$ \\
35123 (CP72-1210) & $2693.2 \pm 21.5$ & $2651.3 \pm 65.3$ & $2604.4 \pm 34.6$ \\
$\begin{array}{l}\text { Nontransformed (CP72- } \\
\text { 1210) }\end{array}$ & $6.7 \pm 0.5$ & $10.4 \pm 0.6$ & $9.2 \pm 0.4$ \\
\hline
\end{tabular}

${ }^{a}$ Average GUS activity was measured in culm top, middle and bottom sections of 1-year-old sugarcane transgenic for SCBV21:GUS. The number of independent SCBV21:GUS transgenic lines tested was five (The range of copy number of GUS in these lines is 8-14). GUS activity represents six technical repetitions and is reported with the standard error

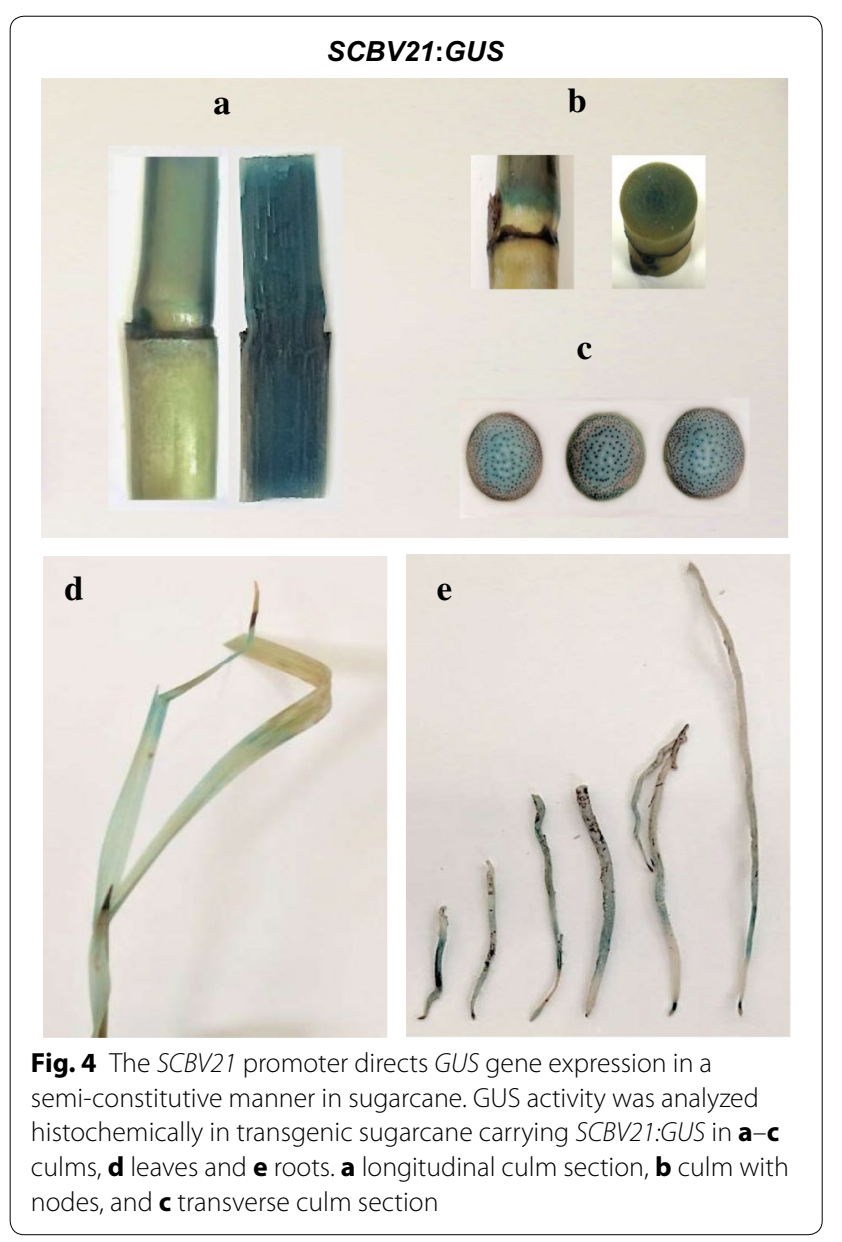

and stable expression analyses using $S C B V 21$ fusions to EYFP and GUS genes (SCBV21:EYFP and SCBV21:GUS) showed that the promoter is functional in both monocots (sugarcane and sweet sorghum) and dicots ( $N$. benthamiana and lima bean), consistent with the activity of the $S C B V$ promoters from SCBMOV-MOR [19, 20, 30, 56] and SCBIMV-QLD species [57].

\section{Sequence relatedness of SCBV21 to other related SCBV and BSV}

Similar to other badnaviruses, SCBV are genetically diverse, and the large pool of SCBV variants present in sugarcane is probably due to the vegetative nature of propagation of the host and its long history of movement and cultivation [57]. The extensive genetic diversity of SCBV has been reported in the promoter [57], RT/RNase $\mathrm{H}$ [29], and full genomic [25] sequences. In this study, we cloned, mapped, and functionally characterized a novel SCBV promoter, $S C B V 21$, in addition to two SCBV promoters previously developed from SCBIMV-QLD [57] and SCBMOV-MOR [19, 20]. SCBV21 shared low nt sequence identity with the published SCBIMV-QLD and SCBMOV-MOR promoters, respectively based on the full promoter sequence, showing that it is a distinct promoter [58]. SCBV21 is also different in its RT/RNase H region (872 nt), a common taxonomic marker for species demarcation in the family Caulimoviridae [27], since it shared only $56.5-88.7$ and $56.0-60.0 \%$ nt sequence identity with 12 other SCBV and three BSV published isolates. Furthermore, the $S C B V 21$ sequence in the genomic intergenic region (a PPR), particularly in the first TATAbox motif showed more divergence than that of the other SCBV and BSV isolates.

\section{Regulatory region of SCBV21}

Common core promoter sequences usually contain an initiator and a TATA-box as well as specific cis-acting regulatory elements interacting with various enhancers or TFs [2]. Our deletion analysis revealed that the 710nt region containing PPR2 [with TSS2 and TATA-box (ATATAA)] at the $3^{\prime}$ end of $S C B V 21$ retained the full promoter activity, suggesting that the RT/RNase $\mathrm{H}$ coding region and putative PPR1 [with TSS1 and TATAbox (TATAAAT)] may not be required for $S C B V 21$ activity. Similarly, previous studies have reported that $\mathrm{RT} / \mathrm{RNase} \mathrm{H}$ was not influenced by important promoter motifs, such as those identified in the SCBMOVMOR or SCBIMV-QLD promoters [19, 57]. However, 


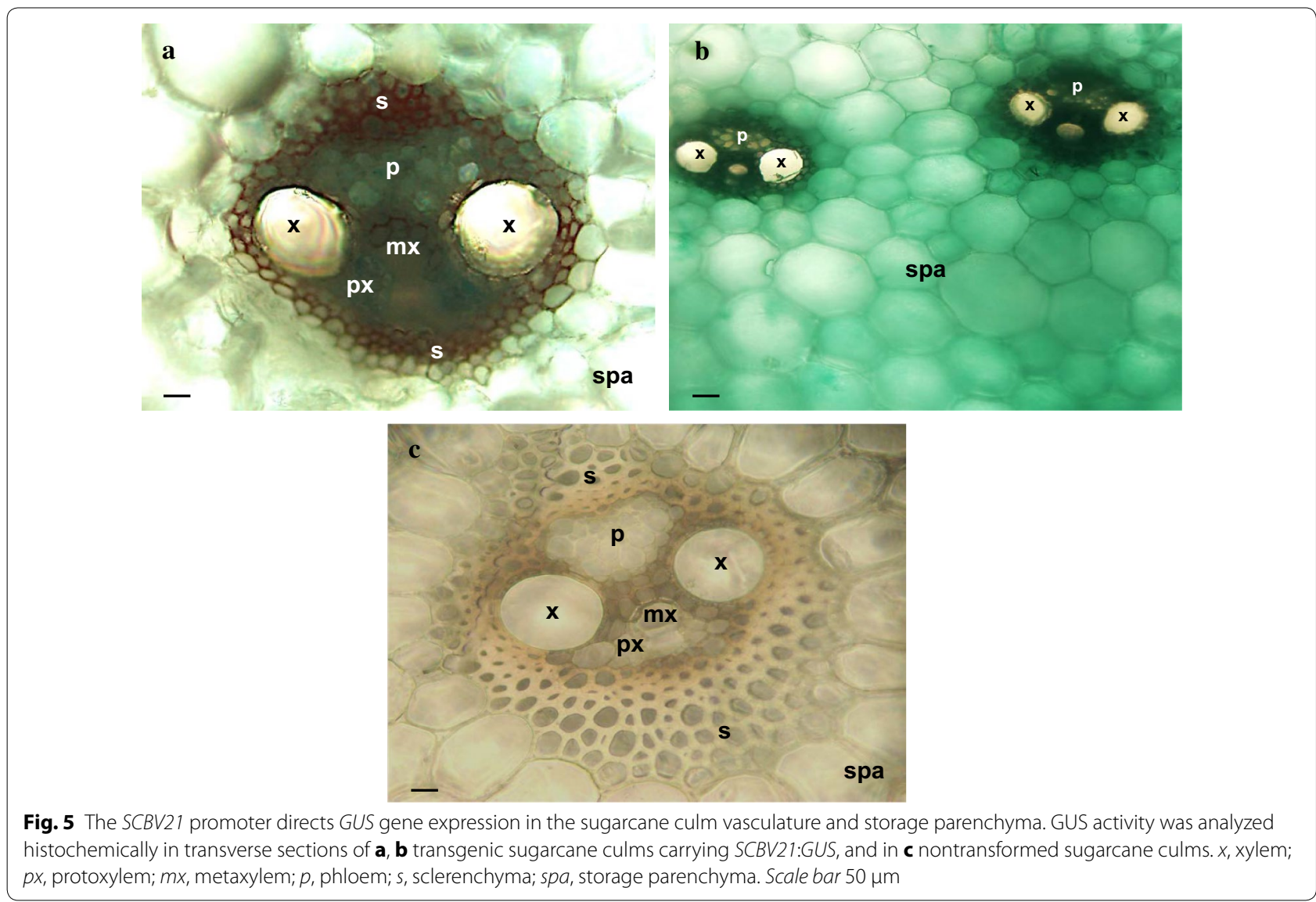

SCBMOV-MOR-derived promoters ScBV-1 and ScBV-2, which lacked the TATA-box sequence at PPR2 conferred a decreased GUS expression level [19]. Furthermore, deletion of the $5^{\prime}$ end of ScBV-3 promoter did not affect GUS expression until it was close to the 254 bp upstream of the TATA-box at PPR2 [59]. The SCBV839 promoter, derived from SCBIMV-QLD and containing 770 bp upstream of transcript start site $(\mathrm{T})$ conferred a higher GUS activity than SCBV576 (containing 507 bp prior to $\mathrm{T}$ ) and SCBV333 (containing 264 bp prior to T), indicating that putative enhancer sequences are present in the region prior to the TSS [60]. Alternatively, SCBV537 or $S C B V 282$, which contained putative enhancer sequences with no PPR2, increased GUS activity when fused with the truncated maize alcohol dehydrogenase 1 promoter [60]. These results demonstrate that PPR2 is critical for promoter activity, and some enhancer sequences upstream PPR2 are potential regulatory elements. Alignment of PPR2 sequence of SCBV21 with those of 12 SCBV and 3 BSV published isolates revealed that the TATA-box (ATATAA) motif has conserved cis-acting elements.

\section{Semi-constitutive gene expression}

Histochemical localization of GUS expression in situ and quantitative assessment of GUS activity in transgenic sugarcane provides evidence for a higher activity of $S C B V 21$ in the culm than the leaf and root. The SCBV21 promoter is different in its semi-constitutive expression pattern from the two previously developed SCBV promoters. For instance, the SCBMOV-MOR promoter was shown to confer high levels of constitutive GUS expression in vegetative and reproductive tissues of both monocots (sugarcane, banana, oat, barley, and wheat) and dicots (Arabidopsis and tobacco) [18-20]. However, differences in SCBMOV-MOR promoter specificity were detected among species and tissues, i.e., stronger GUS activity in most tissues of oat and barley than in wheat [30]; and mainly vascular GUS activity in root of banana but constitutive in tobacco [20]. The SCBIMV-QLD promoter was reported to be the strongest in driving reporter gene expression in the leaves, meristems, and roots of glasshouse-grown sugarcane [57]. The SCBV21 promoter shares more nt sequence homology with the SCBIMV-QLD promoter and, similarly, it is active in 
leaves and roots and contains several putative meristem-regulated motifs (CAT-box) and enhancer elements (CAAT-box) [50, 51]. However, the activity of SCBV21 in these tissues is stronger than that of the SCBIMV-QLD promoter, which conferred equal to or non-significantly higher expression levels of the neomycin phosphotransferase II gene than those measured for Ubi1 in sugarcane [57].

\section{Preferential gene expression in the culm vascular bundle and storage parenchyma}

The vascular-regulated GUS expression pattern of $S C B V 21$ is similar to the one displayed by other badnavirus-derived promoters [14, 16-20]. Some badnaviruses are limited to the vascular tissue like RTBV that replicates only in phloem cells of its host and its promoter drives a strong phloem-specific gene expression [14]. However, other badnaviruses like SCBV, infecting economically important species in the Poaceae family, are not phloem-limited [19]; for instance, the expression profile of the $S C B V 21$ promoter in the vascular bundle, including the phloem cells and the storage parenchyma provides evidence for a more widespread vascular expression than that of RTBV. In addition, SCBV21 displays a significant strong activity in the culm storage parenchyma, not reported for the existing SCBV promoters from SCBIMV-QLD and SCBMOV-MOR species.

The vascular-regulated activity of $S C B V 21$ in the culm correlates with the presence of vascular tissue-specific regulatory motifs in its sequence. These motifs include the ASL-box (CTTTA repeat), present in phloem-specific promoters $[52,53]$ as well as four motifs of plant TFs associated with biological process of phloem histogenesis [54, 55], with three harbored in the PPR1 and PPR2 region. Phloem-regulated expression can be beneficial in imposing a decreased metabolic load on the plant by incorporation of additional phloem-derived cells to ensure proper transport of organic nutrients to cells involved in the reinforcement of the plant axis to counteract the increased weight of the growing plant [61].

The significant $S C B V 21$-driven expression in the storage parenchyma of the vascular bundle of the culm is of major importance to the economic value of crops like sugarcane, energy cane, and other high biomass and fiber producers. The economic yield of sugarcane is determined by accumulation of sucrose in the culm, and the sucrose and hexoses are taken up by the storage parenchyma cells [62]. Under conditions favoring sucrose accumulation, the storage parenchyma tissue of sugarcane can store sucrose up to the maximum value of $62 \%$ dry weight or $27 \%$ fresh weight in theory $[62,63]$. SCBV21 could be advantageous in manipulating certain aspects of sucrose transport and fiber synthesis, and the spatial separation or partitioning between sucrose accumulation and cell wall fiber synthesis. In particular, the GUS expression pattern of $S C B V 21$ is similar to the green fluorescent protein expression pattern displayed by the promoter of the cell wall synthesis gene ShCesA 7 in the storage parenchyma of the maturing culm internode of sugarcane [64]. The use of $S C B V 21$ in co-targeting an elevated expression of primary cell wall synthesis genes (ShCesA1, ShCesA7, ShCesA9 and Shbk2l3) and sugar transporter genes (ShPST2a, ShPST2b, and ShSUT4) [64] in the storage parenchyma would maximize sucrose production and biomass accumulation.

The vascular-regulated expression may be also exploited to develop virus-resistant lines by fusing antiviral constructs to $S C B V 21$ to control monocot viruses that multiply and translocate in the vascular tissue [65], or to improve plant tolerance to important pests such as the neonate sugarcane borer (Diatraea saccharalis F.) larvae by driving the expression of the Bacillus thuringiensis $\delta$-endotoxin [66]. SCBV21 is also potentially useful in other sugarcane biotechnology applications, such as in enhancing the expression of high-value recombinant proteins in the culm of high biomass producers like sugarcane and energy cane [67].

\section{Conclusions}

In this study, a novel plant viral promoter, $S C B V 21$ (1816 bp) was PCR amplified from the genomic DNA of a commercial sugarcane variety infected with a Texan SCBV isolate, with the aim to expand the repertoire of promoters available for use in monocots such as sugarcane, a major sucrose accumulator and biomass producer. Deletion analysis of $S C B V 21$ revealed that the 710-nt region containing PPR2 [with TSS2 and TATAbox (ATATAA)] at its $3^{\prime}$ end retained the full promoter activity, suggesting that the RT/RNase $\mathrm{H}$ region and putative PPR1 may not be required for $S C B V 21$ activity. Stable expression analyses demonstrated that $S C B V 21$ conferred a preferential GUS gene expression in the storage parenchyma surrounding the vascular bundle and in vascular phloem and sclerenchyma of the sugarcane culm. It is further shown that $S C B V 21$ exhibited significantly higher levels of GUS gene expression than the common maize Ubi1 and CaMV $35 \mathrm{~S}$ promoters. The novel $S C B V 21$ promoter expression pattern is distinct from that of the few existing $S C B V$ promoters in its strong activity in the culm vascular bundle and its storage parenchyma, making it valuable for metabolic engineering to improve plant biomass characteristics through enhanced carbon metabolism for sugar accumulation or increased fiber content for biofuel feedstock. 


\section{Additional files}

Additional file 1: Table S1. List of primers used for cloning the SCBV21 promoter and its deletions.

Additional file 2: Figure S1. Multiple alignment of nucleotide sequences of the SCBV21 promoter (KY031904) and the two published SCBIMV-QLD (NC_003031) and SCBMOV-MOR (NC_008017) promoter regions. Two potential promoter regions of SCBV21 are underlined in red, as identified with Neural Network Promoter Prediction (NNPP, version 2.2). The putative transcription start sites TSS1 and TSS2 within the two regions are marked with an asterisk ${ }^{*}$ ). The two TATA-boxes (TATAAAT and ATATAA) that were predicted by PlantCARE and PLACE databases are indicated in a red box. The partial RT/RNAse $\mathrm{H}$ region (782 nucleotides) is indicated in a green box. Nucleotides that are highlighted in black have the highest percentage identity.

Additional file 3: Figure S2. Map of promoter:gene constructs used for sugarcane transformation. SCBV21: Sugarcane bacilliform virus promoter; Ubil: Maize ubiquitin 1 promoter: Pr4: Ubil promoter without heat-shock elements (5'-TGGACCCCTCTCGAGAGTTCCGCTC-3'); E35S: Enhanced Cauliflower mosaic virus (CaMV) 35S (2×35S) promoter; EYFP: enhanced yellow fluorescent protein gene; GUS: $\beta$-glucuronidase gene; Nos: Agrobacterium tumefaciens nopaline synthase terminator. Ubi1:GUS (pAHC27 vector) [3] and CaMV 35S:GUS (pBI221 vector) (Clontech, Takara Bio USA, Inc., Mountain View, CA, USA) are used. B, BamHl; Bb, Bbsl; E, EcoRl; H, Hindlll; N, Ncol; P, Pstl; Sa, Sall; Sc, Sacl; Sm, Smal; Sp, Sphl; X, Xbal; Xh, Xhol; and Xm, $X$ mal. Unique enzyme sites are indicated in red. Boxes are not drawn to scale. A triangle represents the deletion of heat-shock elements (25 bp) in the Ubil promoter.

Additional file 4: Table S2. Identity (\%) of nucleotide sequences of partial reverse transcriptase/ribonulcease H (RT/RNAse H) region (872 nt) of Sugarcane bacilliform virus (SCBV) promoter (SCBV21), and 12 SCBV and three Banana streak virus published isolates.

Additional file 5: Figure S3. Transient expression of EYFP and GUS genes as directed by the SCBV21 promoter in monocot and dicot tissues. a-f fluorescent images and $\mathbf{g}$-I color images were collected with a stereomicroscope (Olympus SZX7, Olympus, Center Valley, PA, USA) fitted with YFPHQ filters (excitation of 490-500 nm and emission of 515-560 nm) and a DP71 digital camera (Olympus) $(9.5 \times, 15 \times$ or $24 \times$ magnification) with YFP filter and blank light, respectively at $48 \mathrm{~h}$ post-DNA bombardment with SCBV21:EYFP or SCBV21:GUS (scale bar $1.0 \mathrm{~mm}$ ). a and $\mathbf{g}$ sugarcane leaf roll disc, $\mathbf{b}$ and $\mathbf{h}$ sugarcane culm, $\mathbf{c}$ and $\mathbf{i}$ sugarcane root, $\mathbf{d}$ and $\mathbf{j}$ sweet sorghum leaf, e and $\mathbf{k}$ tobacco leaf, $\mathbf{f}$ and $\mathbf{I}$ lima bean cotyledon.

\section{Abbreviations}

BSV: Banana streak virus; CaMV: Cauliflower mosaic virus; DMF: N,N-dimethylformamide; EDTA: ethylenediaminetetraacetic acid; EYFP: enhanced yellow fluorescent protein; GUS: $\beta$-glucuronidase; NOS: Agrobacterium tumefaciens nopaline synthase; MS: Murashige and Skoog medium; pSK: pBluescript; RT/RNase H: reverse transcriptase/ribonuclease H; PPR: potential promoter region; RTBV: Rice tungro bacilliform virus; SCBIMV-QLD: Sugarcane bacilliform IM virus-Queensland; SCBMOV-MOR: Sugarcane bacilliform MO virus-Morocco; TF: transcription factor; TSS: transcription start site; Ubi1: maize ubiquitin 1; X-Gluc: 5-bromo-4-chloro-3-indolyl- $\beta$-o-glucuronic acid.

\section{Authors' contributions}

SJG, MBD, and JWP performed most of the experiments, acquisition and interpretation of data, and crafting and critical revision of the manuscript. XBW and SRS were involved in carrying out part of the experimental study and data analysis. RKC participated in critical revision of the manuscript. TEM acted as a coordinator of the project, designed this study, analyzed experimental data, drafted, and revised the manuscript. All authors read and approved the final manuscript.

\section{Author details}

${ }^{1}$ National Engineering Research Center for Sugarcane, Fujian Agriculture and Forestry University, Fuzhou 350002, Fujian, China. ${ }^{2}$ Texas A\&M AgriLife
Research, Weslaco, TX 78596, USA. ${ }^{3}$ Guangdong Key Lab of Sugarcane Improvement \& Biorefinery, Guangzhou Sugarcane Industry Research Institute, Guangzhou 510316, Guangdong, China.

\section{Acknowledgements}

We gratefully acknowledge Denise Rossi, Soledad Al-Varez and Hyun Park Kang for excellent technical assistance. We sincerely thank Dr. Guo-Hui Zhou (South China Agricultural University) for kindly providing the Prom-F and Prom-R primers and Dr. Xiaofeng Wang (Virginia Tech University) for his constructive suggestions in manuscript preparation.

\section{Competing interests}

The authors declare that they have no competing interests.

\section{Availability of data and materials}

The datasets supporting the conclusions of this manuscript are included within the article and its additional files.

\section{Funding}

This study was funded in part by an Earmark Fund from the China Agriculture Research System (CARS-20-2-4) and the Major Science and Technology Project of Fujian Province (No. 2015NZ0002-2) in China.

\section{Publisher's Note}

Springer Nature remains neutral with regard to jurisdictional claims in published maps and institutional affiliations.

Received: 9 January 2017 Accepted: 16 June 2017

Published online: 04 July 2017

\section{References}

1. Zeevi V, Liang Z, Arieli U, Tzfira T. Zinc finger nuclease and homing endonuclease-mediated assembly of multigene plant transformation vectors. Plant Physiol. 2012;158:132-44.

2. Peremarti A, Twyman RM, Gómez-Galera S, Naqvi S, Farré G, Sabalza M, Miralpeix B, Dashevskaya S, Yuan D, Ramessar K, Christou P, Zhu C, Bassie $\mathrm{L}$, Capell T. Promoter diversity in multigene transformation. Plant Mol Biol. 2010;73:363-78.

3. Christensen AH, Quail PH. Ubiquitin promoter-based vectors for highlevel expression of selectable and/or screenable marker genes in monocotyledonous plants. Transgenic Res. 1996;5:213-8.

4. Wei $\mathrm{H}$, Wang ML, Moore PH, Albert HH. Comparative expression analysis of two sugarcane polyubiquitin promoters and flanking sequences in transgenic plants. J Plant Physiol. 2003;160:1241-51.

5. Liu AW, Oard SV, Oard JH. High transgene expression levels in sugarcane (Saccharum officinarum L.) driven by the rice ubiquitin promoter RUBQ2. Plant Sci. 2003;165:743-50.

6. Philip A, Syamaladevi DP, Chakravarthi M, Gopinath K, Subramonian N. $5^{\prime}$ regulatory region of ubiquitin 2 gene from Porteresia coarctata makes efficient promoters for transgene expression in monocots and dicots. Plant Cell Rep. 2013;32:1199-210.

7. Chakravarthi M, Philip A, Subramonian N. Truncated ubiquitin $5^{\prime}$ regulatory region from Erianthus arundinaceus drives enhanced transgene expression in heterologous systems. Mol Biotechnol. 2015:57:820-35

8. Morais LK, Aguiar MS, Silva PAE, Camara TMM, Cursi DE, Fernande AR Jr, Chapola RG, Carneiro MS, Bespalhok Filho JC. Breeding of sugarcane. In: Cruz VMV, Dierig DA, editors. Industrial crops, handbook of plant breeding 9. New York: Springer; 2015. p. 29-42.

9. Damaj MB, Kumpatla SP, Emani C, Beremand PD, Reddy AS, Rathore KS, Buenrostro-Nava MT, Curtis IS, Thomas TL, Mirkov TE. Sugarcane DIRIGENT and O-methyltransferase promoters confer stem-regulated gene expression in diverse monocots. Planta. 2010;231:1439-58.

10. Harrison MD, Geijskes J, Coleman HD, Shand K, Kinkema M, Palupe A, Hassall R, Sainz M, Lloyd R, Miles S, Dale JL. Accumulation of recombinant cellobiohydrolase and endoglucanase in the leaves of mature transgenic sugar cane. Plant Biotechnol J. 2011;9:884-96. 
11. Kinkema M, Miles S. Compositions and methods for increased expression in sugar cane. Patent application WO/2013/090137. 2013.

12. Moyle RL, Birch RG. Sugarcane loading stem gene promoters drive transgene expression preferentially in the stem. Plant Mol Biol. 2013;82:51-8

13. Kay R, Chan A, Daly M, McPherson J. Duplication of CaMV 355 promoter sequences creates a strong enhancer for plant genes. Science. 1987;236:1299-302.

14. Bhattacharyya-Pakrasi M, Peng J, Elmer JS, Laco G, Shen P, Kaniewska MB, Kononowicz H, Wen F, Hodges TK, Beachy RN. Specificity of a promoter from the Rice tungro bacilliform virus for expression in phloem tissues. Plant J. 1993;4:71-9.

15. Chen G, Rothnie HM, He X, Hohn T, Fütterer J. Efficient transcription from the Rice tungro bacilliform virus promoter requires elements downstream of the transcription start site. J Virol. 1996;70:8411-21.

16. Medberry SL, Lockhart BEL, Olszewski NE. The Commelina yellow mottle virus promoter is a strong promoter in vascular and reproductive tissue. Plant Cell. 1992:4:185-92.

17. Yang IC, lommarini JP, Becker DK, Hafner GJ, Dale JL, Harding RM. A promoter derived from taro bacilliform badnavirus derives strong expression in transgenic banana and tobacco plants. Plant Cell Rep. 2003;21:1199-206.

18. Schenk PM, Remans T, Sági L, Elliott AR, Dietzgen RG, Swennen R, Ebert PR, Grof CP, Manners JM. Promoters for pregenomic RNA of Banana streak badnavirus are active for transgene expression in monocot and dicot plants. Plant Mol Biol. 2001:47:399-412.

19. Tzafrir I, Torbert KA, Lockhart BEL, Somers DA, Olszewski NE. The sugarcane bacilliform badnavirus promoter is active in both monocots and dicots. Plant Mol Biol. 1998;38:347-56.

20. Schenk PM, Sagi L, Remans T, Dietzgen RG, Bernard MJ, Graham MW, Manners JM. A promoter from sugarcane bacilliform badnavirus drives transgene expression in banana and other monocot and dicot plants. Plant Mol Biol. 1999;39:1221-30.

21. Bouhida M, Lockhart BEL, Olszewski NE. An analysis of the complete sequence of a Sugarcane bacilliform virus genome infectious to banana and rice. J Gen Virol. 1993;74:15-22.

22. Geijskes RJ, Braithwaite KS, Dale JL, Harding RM, Smith GR. Sequence analysis of an Australian isolate of sugarcane bacilliform badnavirus. Arch Virol. 2002;147:2393-404.

23. Muller E, Dupuy V, Blondin L, Bauffe F, Daugrois JH, Nathalie L, IskraCaruana ML. High molecular variability of Sugarcane bacilliform viruses in Guadeloupe implying the existence of at least three new species. Virus Res. 2011;160:414-9.

24. Karuppaiah R, Viswanathan R, Kumar VG. Genetic diversity of Sugarcane bacilliform virus isolates infecting Saccharum spp. in India. Virus Genes. 2013:46:505-16.

25. Sun S-R, Damaj MB, Alabi OJ, Wu X-B, Mirkov TE, Fu H-Y, Chen R-K, Gao S-J. Molecular characterization of two divergent variants of sugarcane bacilliform viruses infecting sugarcane in China. Eur J Plant Pathol. 2016;145:375-84.

26. Adams MJ, Carstens EB. Ratification vote on taxonomic proposals to the International Committee on Taxonomy of Viruses. Arch Virol. 2012;157:1411-22.

27. Geering ADW, Hull R. Family Caulimoviridae. In: King AMQ, Adams MJ, Carestens EB, Lefkowitz EJ, editors. Virus taxonomy classification and nomenclature of viruses ninth report of the international committee on taxonomy of viruses. San Diego: Elsevier; 2012. p. 424-43.

28. Rao GP, Sharma SK, Singh D, Arya M, Singh P, Baranwal VK. Genetically diverse variants of Sugarcane bacilliform virus infecting sugarcane in India and evidence of a novel recombinant badnavirus variant. J Phytopathol. 2014;162:779-87.

29. Wu X-B, Alabi OJ, Damaj MB, Sun S-R, Mirkov TE, Fu H-Y, Chen R-K, Gao S-J. Prevalence and RT/RNase H genealogy of Sugarcane bacilliform virus isolates from China. J Phytopathol. 2016;164:595-607.

30. Al-Saady NA, Torbert KA, Smith L, Makarevitch I, Baldridge G, Zeyen RJ, Muehlbauer GJ, Olszewski NE, Somers DA. Tissue specificity of the Sugarcane bacilliform virus promoter in oat, barley and wheat. Mol Breed. 2004; $14: 331-8$.

31. Ingelbrecht IL, Irvine JE, Mirkov TE. Posttranscriptional gene silencing in transgenic sugarcane. Dissection of homology-dependent virus resistance in a monocot that has a complex polyploid genome. Plant Physiol. 1999;119:1187-98.
32. Mudge SR, Osabe K, Casu RE, Bonnett GD, Manners JM, Birch RG. Efficient silencing of reporter transgenes coupled to known functional promoters in sugarcane, a highly polyploid crop species. Planta. 2009;229:549-58.

33. Birch RG, Shen B, Sawyer BJ, Huttner E, Tucker WQ, Betzner AS. Evaluation and application of a luciferase fusion system for rapid in vivo analysis of RNAi targets and constructs in plants. Plant Biotechnol J. 2010;8:465-75.

34. Gao SJ, Damaj MB, Park JW, Beyene G, Buenrostro-Nava MT, Molina J, Wang X, Ciomperlik JJ, Manabayeva SA, Alvarado VY, Rathore KS, Scholthof HB, Mirkov TE. Enhanced transgene expression in sugarcane by co-expression of virus-encoded RNA silencing suppressors. PLoS ONE. 2013;8:e66046

35. Reese MG. Application of a time-delay neural network to promoter annotation in the Drosophila melanogaster genome. Comput Chem. 2001;26:51-6.

36. Lescot $M$, Déhais $P$, Thijs $G$, Marchal $K$, Moreau $Y$, Van de Peer $Y$, Rouzé $P$, Rombauts S. PlantCARE, a database of plant cis-acting regulatory elements and a portal to tools for in silico analysis of promoter sequences. Nucleic Acids Res. 2002;30:325-7.

37. Higo K, Ugawa Y, Iwamoto M, Korenaga T. Plant cis-acting regulatory DNA elements (PLACE) database. Nucleic Acids Res. 1999;27:297-300.

38. Jin JP, Tian F, Yang DC, Meng YQ, Kong L, Luo JC, Gao G. PlantTFDB 4.0: toward a central hub for transcription factors and regulatory interactions in plants. Nucleic Acids Res. 2017;45(D1):D1040-5.

39. Tamura K, Stecher G, Peterson D, Filipski A, Kumar S. MEGA6: molecular evolutionary genetics analysis version 6.0. Mol Biol Evol. 2013;30:2725-9.

40. Hall TA. BioEdit: a user-friendly biological sequence alignment editor and analysis program for Windows 95/98/NT. Nucleic Acids Symp Ser. 1999:41:95-8.

41. Beyene G, Buenrostro-Nava MT, Damaj MB, Gao S-J, Molina J, Mirkov TE. Unprecedented enhancement of transient gene expression from minimal cassettes using a double terminator. Plant Cell Rep. 2011;30:13-25.

42. Murashige T, Skoog F. A revised medium for rapid growth and bioassays with tobacco tissue cultures. Physiol Plant. 1962;15:473-97.

43. Snyman SJ, Meyer GM, Richards JM, Haricharan N, Ramgareeb S, Huckett BI. Refining the application of direct embryogenesis in sugarcane: effect of the developmental phase of leaf disc explants and the timing of DNA transfer on transformation efficiency. Plant Cell Rep. 2006;25:1016-23.

44. Chiera JM, Bouchard RA, Dorsey SL, Park EH, Buenrostro-Nava MT, Ling PP, Finer JJ. Isolation of two highly active soybean (Glycine max (L.) Merr.) promoters and their characterization using a new automated image collection and analysis system. Plant Cell Rep. 2007;26:501-1509.

45. Tai TH, Tanksley SD. A rapid and inexpensive method for isolation of total DNA from dehydrated plant tissue. Plant Mol Biol Rep. 1990;8:297-303.

46. Sambrook J, Russell DW. Molecular cloning: a laboratory manual. New York: Cold Spring Harbor Laboratory Press; 2001. p. 2344.

47. Sambrook J, Fritsch E, Maniatis T. Molecular cloning: a laboratory manual. New York: Cold Spring Harbor Laboratory Press; 1989.

48. Mangwende T, Wang ML, Borth W, Hu J, Moore PH, Mirkov TE, Albert HH. The PO gene of Sugarcane yellow leaf virus encodes an RNA silencing suppressor with unique activities. Virology. 2009;384:38-50.

49. Jefferson RA, Kavanagh TA, Bevan MW. GUS fusions: $\beta$-glucuronidase as a sensitive and versatile gene fusion marker in higher plants. EMBO J. 1987;6:3901-7

50. Ow DW, Jacobs JD, Howell SH. Functional regions of the cauliflower mosaic virus $35 \mathrm{~S}$ RNA promoter determined by use of the firefly luciferase gene as a reporter of promoter activity. Proc Natl Acad Sci USA. 1987;84:4870-4.

51. Porto MS, Pinheiro MP, Batista VG, dos Santos RC, de Albuquerque Melo Filho P, de Lima LM. Plant promoters: an approach of structure and function. Mol Biotechnol. 2014;56:38-49.

52. Yin $Y$, Chen L, Beachy R. Promoter elements required for phloem-specific gene expression of the RTBV promoter in rice. Plant J. 1997;12:1179-88.

53. Saha P, Chakraborti D, Sarkar A, Dutta I, Basu D, Das S. Characterization of vascular-specific RSs1 and rolC promoters for their utilization in engineering plants to develop resistance against hemipteran insect pests. Planta. 2007;226:429-42

54. Prigge MJ, Clark SE. Evolution of the class III HD-Zip gene family in land plants. Evol Dev. 2006;8:350-61.

55. Alexandrov NN, Brover WV, Freidin S, Troukhan ME, Tatarinova TV, Zhang H, Swaller TJ, Lu YP, Bouck J, Flavell RB, Feldmann KA. Insights into corn genes derived from large-scale cDNA sequencing. Plant Mol Biol. 2009;69:179-94. 
56. Samac DA, Tesfaye M, Dornbusch M, Saruul P, Temple SJ. A comparison of constitutive promoters for expression of transgenes in alfalfa (Medicago sativa). Transgenic Res. 2004;13:349-61.

57. Braithwaite KS, Geijskes RJ, Smith GR. A variable region of the Sugarcane bacilliform virus (SCBV) genome can be used to generate promoters for transgene expression in sugarcane. Plant Cell Rep. 2004;23:319-26.

58. Mirkov ET, Park JW, Gao SJ. Compositions, organisms, systems, and methods for expressing a gene product in plants using SCBV expression control sequences operable in monocots and dicots. United States Patent 8710207. 2014.

59. Al-Saady NA, Gopalraj M, Olszewski NE, Somers DA. Deletion analysis of the Sugarcane bacilliform virus promoter activity in monocot and dicot plants. Biotechnology. 2010;9:283-93.

60. Davies JP, Reddy V, Liu XL, Reddy AS, Ainley WM, Thompson M, SastryDent L, Cao Z, Connell J, Gonzalez DO, Wagner DR. Identification and use of the Sugarcane bacilliform virus enhancer in transgenic maize. BMC Plant Biol. 2014;14:359.

61. Tornero P, Conejero V, Vera P. Phloem-specific expression of a plant homeobox gene during secondary phases of vascular development. Plant $J$ 1996;9:639-48.
62. Sachdeva M, Bhatia S, Batta SK. Sucrose accumulation in sugarcane: a potential target for crop improvement. Acta Physiol Plant. 2011;33:1571-83.

63. Bull TA, Glasziou KT. The evolutionary significance of sugar accumulation in Saccharum. Aust J Biol Sci. 1963;16:737-42.

64. Casu RE, Rae AL, Nielsen JM, Perroux JM, Bonnett GD, Manners JM. Tissue-specific transcriptome analysis within the maturing sugarcane stalk reveals spatial regulation in the expression of cellulose synthase and sucrose transporter gene families. Plant Mol Biol. 2015;89:607-28.

65. Graham MW, Craig S, Waterhouse PM. Expression patterns of vascularspecific promoters RolC and Sh in transgenic potatoes and their use in engineering PLRV-resistant plants. Plant Mol Biol. 1997;33:729-35.

66. Arencibia A, Vázquez RI, Prieto D, Téllez P, Carmona ER, Coego A, Hernández L, de la Riva GA, Selman-Housein G. Transgenic sugarcane plants resistant to stem borer attack. Mol Breed. 1997;3:247-55.

67. Barros GOF, Ballen MAT, Woodard SL, Wilken LR, White SG, Damaj MB, Mirkov TE, Nikolov ZL. Recovery of bovine lysozyme from transgenic sugarcane stalks: extraction, membrane filtration, and purification. Bioprocess Biosyst Eng. 2013;36:1407-16.

\section{Submit your next manuscript to BioMed Central and we will help you at every step:}

- We accept pre-submission inquiries

- Our selector tool helps you to find the most relevant journal

- We provide round the clock customer support

- Convenient online submission

- Thorough peer review

- Inclusion in PubMed and all major indexing services

- Maximum visibility for your research

Submit your manuscript at www.biomedcentral.com/submit 